Please do not quote without permission from the authors

\title{
AN ANALYSIS AND CRITIQUE OF THE BIS PROPOSAL ON CAPITAL ADEQUACY AND RATINGS
}

\author{
Edward I. Altman* \\ and \\ Anthony Saunders*
}

First Draft: 11/99

Second Draft: $1 / 2000 * *$

*The authors are the Max L. Heine and John M. Schiff Professor of Finance, Stern School of Business, NYU. They wish to thank several individuals from Standard \& Poor's and Moody's for their data assistance. The computational assistance of Vellore Vishore and Sreedar Bharath are also acknowledged as well as the coordination by Robyn Vanterpool. The opinions presented are solely of the authors.

**This paper's drafts have been prepared for two symposia on the proposed new guidelines; the first held at the University of Frankfurt on December 2, 1999 and the second at the NYU Salomon Center's Stern School of Business forum, held on February 25, 2000. 
An Analysis and Critique of the BIS Proposal on Capital Adequacy and Ratings

\begin{abstract}
This paper has examined two specific aspects of stage 1 of the (BIS's) Bank for International Settlement's proposed reforms to the $8 \%$ risk-based capital ratio. We argue that relying on "traditional" agency ratings could produce cyclically lagging rather leading capital requirements, resulting in an enhanced rather than reduced degree of instability in the banking and financial system. Despite this possible shortcoming, we believe that sensible risk based weighting of capital requirements is a step in the right direction. The current risk based bucketing proposal, which is tied to external agency ratings, or possibly to internal bank ratings, however, lacks a sufficient degree of granularity. In particular, lumping $A$ and BBB (investment grade corporate borrowers) together with BB and B (below investment grade borrowers) severely misprices risk within that bucket and calls, at a minimum, for that bucket to be split into two. We examine the default loss experience on corporate bonds for the period 1981-1999 and propose a revised weighting system which more closely resembles the actual loss experience on credit assets.
\end{abstract}




\section{Introduction}

In June 1999, the BIS released its long awaited proposal on reform of the $8 \%$ risk-based capital ratio for credit risk that has been in effect since $1993 . \square_{\text {The }} 8 \%$ ratio has been criticized on at least three major grounds. First, it gives an equal risk-weighting to all corporate credits whether of high or low credit quality. Second, it fails to incorporate potential capital savings from credit (loan) portfolio diversification. The latter is a result of its simple additive nature. And third, it has led to extensive regulatory capital arbitrage which adds to the riskiness of bank asset portfolios.

In its June 1999 draft, the BIS proposed a three-stage reform process. ${ }^{[}$In the first stage, the $8 \%$ risk based ratio (where all loans receive the same $100 \%$ risk-weighting) would be replaced by weightings based on the external credit agency rating of the borrower (we discuss this proposal in more detail in Section 2 of the paper). In the second stage, at some unspecified time in the future, when some sophisticated banks have developed their own internal rating systems for loans, a transformation may be made to calculating capital requirements based on a bank's allocation of its loans to the various grades/ratings in its own internal loan rating system. Finally, in the third stage, given appropriate model and data base development and testing, some banks may be able to use their own internal credit risk models to calculate capital requirements. Importantly, these internal models allow for portfolio diversification effects.

A number of issues have been raised about stages two and three of the reform proposal e.g., how will the internal rating systems of different banks----especially if they continue to develop independently of each other----be grouped into some standardized set of capital risk

\footnotetext{
${ }^{1}$ The $8 \%$ ratio was phased-in over the 1988-1992 period, following the 1988 Basel Accord. Some countries have actually adopted a capital adequacy ratio of over $8 \%$ (e.g., Brazil uses 11\%). In all cases, the level of capital is to help to ensure a banks solvency against unexpected losses.

${ }^{2}$ The discussion period for the proposal runs until March 2000. A revised proposal will then be distributed with a subsequent second, probably shorter, discussion and commentary period.
} 
weights; that is will a rating of 1 for Citigroup be the same as a 1 for BankAmerica or will a rating of 1 for a bank in the United States be equivalent to a 1 for a bank in Germany? $?^{3}$ Also, what is the appropriate mapping of the internal rating model with external ratings? While these are important issues, this paper concentrates on the first stage of the proposal. In particular, we raise a number of concerns (backed by data) regarding the use of rating agencies rating systems in a reformed capital adequacy system in the manner that the 1999 BIS proposal stipulates.

Section 2 of this paper briefly outlines the BIS stage-one proposal. Section 3 presents some empirical evidence that questions the proposal and shows that similar "risk-shifting" incentives (i.e., regulatory capital arbitrage) exist under the new plan as under the current $8 \%$ risk-based capital ratio. These empirical tests are supplemented by simulations on sample data to better assess expected and unexpected losses form actual bond portfolios. We will show that the current Basel "one size fits all" approach is not sufficiently modified in the new approach. Finally, Section 4 provides our recommendation to enlarge the number of "buckets" with different risk weightings to better approximate actual loss experience and risk categories.

\section{The BIS Stage 1 Proposal}

Table 1 shows the proposed reform of the $8 \%$ ratio in stage 1 of the new plan. As noted in the introduction, currently all corporate loans have the same $100 \%$ risk-weight (for risk adjusted assets) implying the same minimum capital requirement (e.g., 8\%). Under the new proposal, corporate borrowers rated AAA to AA - by S \& $\mathrm{P}$, or the equivalent authorized rating agencies (see Table 2), will have a risk weight of $20 \%$. This implies a capital ratio of $.2 \times 8 \%=1.6 \%$; much lower than at present for "high quality" loans. In what follows, we shall label this category "bucket 1." For corporate borrowers rated A+ to B-, the risk weight will remain at 100\%, i.e.,

\footnotetext{
${ }^{3}$ See W. Tracey and M. Carey (1998) for a discussion and survey of banks' internal ratings systems. A more recent discussion paper by the Basel Committee on Banking Supervision (2000) examines the range of Banks' internal rating systems.
} 
they will continue to have a capital ratio of $8 \%$; we will call this group of borrowers "bucket $2 . "$ For those borrowers rated below B-, the risk weighting increases to $150 \%$, implying a capital ratio of $1.5 \times 8 \%=12 \%$. It might be noted that, somewhat paradoxically, unrated corporate borrowers are given a lower $100 \%$ risk weight and thus an $8 \%$ capital requirement. A similar, but less broad bucketing approach is adopted for sovereigns and banks. In particular, the current system of a zero risk weight for OECD countries and a 100\% risk-weight for all other countries is replaced by four new buckets based on agency ratings.

In the next Section, we use data on bond ratings, defaults and loss rates to more closely examine the three-bucket approach for corporate borrowers. We do this with two questions in mind. First, does this approach lead to bank capital reserves rising prior to recessions, i.e., before the realization of loan losses typically occurs -- as should happen under an "ideal" system? In particular, a well-designed regulatory system should see capital rising during periods of high profitability and earnings for banks (which normally coincides with periods of business expansions) and falling during recessions as "unexpected losses" are written off against capital. At the very least, the size of the capital reserve should be coincident with the business cycle even if it does not lead it.

Second, does the bucketing system make economic sense? That is, how homogeneous in terms of risk are the different buckets. For example, bucket 2 encompasses both investment grade debt (A and BBB) as well as below investment grade debt (BB and B). Moreover, if they are not homogenous, what relative risk-weighting scheme would these data suggest? 


\section{Empirical Results}

In this section we use data from Moody's and Standard \& Poor's and from the NYU Salomon Center's data base on Corporate bond defaults ${ }^{4}$ and losses on defaults in order to gain insight into these two questions.

\subsection{The Lead-Lag Relationship of Capital Reserves}

As discussed above, ideally, capital reserves for unexpected losses should be accumulated during periods of high bank profitability and business expansion. Banks find it much more difficult, if not impossible, to add substantially to their capital reserves when profits are low and the economy is in recession. And, reserves should be adequate prior to, not after defaults and losses increase.

In Figure 1, we have used Moody's bond ratings to group bonds outstanding over the March 1989 to March 1999 period into the three buckets implied by the Moody's equivalents to the S\&P ratings shown in Table 1. The period 1989-1991 is a period of recession while the period of the current expansion begins post-1992. Although these data include only one recession, they are representative of a number of recent critiques that have found that rating agencies move slowly and their ratings are often inflexible. As a result, external ratings' ability to predict default with a long (if any) lead has been questioned. Indeed, Figure 1 suggests that a capital adequacy system built around traditional agency ratings might even follow, rather than lead, the business cycle. As can be seen, the proportion of bonds in bucket 2 appear to fall continuously over the March 1989 to March 1991 period, while those in Buckets 1 and 3 appear to rise continuously. Specifically, the proportion of bonds in bucket 3, with the $150 \%$ risk

\footnotetext{
${ }^{4}$ The data includes defaults on straight (non-convertible) corporate bonds over the period 1971-1999, ratings and prices on the defaulting issues at birth, one year and one month prior to default as well as just after default.
} 
weight, peaks in September 1991, near the end of the recession rather than at the beginning.

Figure 2 shows a similar result for S\&P ratings. As can be seen, while the percentage of bonds in bucket 3 is small, its proportion still rises over the 1990 to 1991 period. If risk weights and capital requirements were tied to these buckets, this could have meant (had the new proposal been in effect during the 1989-1991 recession) that some banks would have had to build up their minimum reserve requirements during the recession with a peak minimum capital ratio being achieved at or near the recession's end. ${ }^{\mathrm{G}}$ That is, rather than leading the recession, minimum capital requirements would have been lagging it and also the rising wave of loan defaults.

This suggests that alternatives to the rating agencies' bucket approach be assessed. For example, there are a number of rating and default forecasting approaches that have been developed in the last decade. These include ones by Jonsson \& Fridson (1996), Moody's (1999), and Altman (1989). The first two utilize the existing rating proportions and add macroeconomic variables to the forecasting regression. The latter assumes a stable default aging frequency by original rating, and forecasts defaults based on the previous thirty years of default aging experience, in essence a regression-to-the-mean approach.

A second possibility is that the individual issuers of loans be subjected to a micro-default probability model and the aggregate of this bottom-up approach be assessed for expected and unexpected (capital) losses of the loan portfolio. Approaches with this objective include equity value option models (expected default frequencies) and multivariate models which involve financial statement and market equity variables.

\footnotetext{
${ }^{5}$ The years 1990 and 1991 saw defaults rise dramatically in both the corporate loan and bond markets. Indeed, corporate bond default rates in each of those years were over $10 \%$ of the outstanding bonds at the start of each year (see Altman, Cooke \& Kishore, 1999).

${ }^{6}$ A survey of these methods can be found in Altman and Saunders (1997).
} 
A final idea exploits the use of credit spreads to define the buckets. It can be empirically demonstrated that credit spreads were particularly accurate forecasters of subsequent default rates at the start of 1990 and again at the start of 1991$]^{-7}$ The credit spread indicator is a commonly used barometer of risk in financial systems and for economic cycles by both the government and banks.

\subsection{Bucket Risk Homogeneity}

To analyze the second question, bucket risk homogeneity, we examined data on bond issues (and issuers) over the 1981-1999 (September) period. Our focus of attention was the degree of homogeneity (heterogeneity) of unexpected loss rates over the sample period. Following most approaches of economic capital and loan loss reserve calculations, loan loss reserves are meant to cover expected (or mean) losses while economic capital reserves are meant to cover unexpected losses.

To undertake this study, we collected data on bond issues and issuers that did and did not default, the ratings of those defaulting issues one-year prior to default, the price and coupon of the bonds one year prior to default and the price of the bonds just after default. The price (and coupon) one year prior to default $\left(\mathrm{P}_{\mathrm{t}-1}\right.$ and $\left.\mathrm{C}_{\mathrm{t}-1}\right)$ and the price (and lost coupon) on default ( $\mathrm{P}_{\mathrm{t}}$ and $\mathrm{C}_{t}$ ) allowed us to calculate a loss rate for each bond default (i.e., $\left[\mathrm{P}_{t}-\left(\mathrm{P}_{\mathrm{t}-1}+\mathrm{C}_{\mathrm{t}-1} / 2\right)\right] / \mathrm{P}_{\mathrm{t}-1}$. The total number of defaulting bonds over the 18 year sample period, for which we had full price and rating information, was 588. For an additional 104 bonds, we only had the rating and not the price, one year prior to default. For these bonds, we assumed that their default experience

\footnotetext{
${ }^{7}$ On December 31, 1989 the yield-spread between high yield corporate bonds and ten-year U.S. Treasury bonds was $7.24 \%$ and one year later it was $10.50 \%$ (Table 3). These were the highest levels for several decades and the subsequent annual default rates $(10.1 \%$ and $10.3 \%)$ were the highest default rates on high yield "junk" bonds ever recorded. It should be noted that the highest dollar amount of defaults ( $\$ 23.5$ billion) in this market, perhaps in the commercial loan market as well, occurred in the most recent year (1999), see Altman, et al (2000). Of course, the size of these markets are much greater in 1999 than in the early 1990's. Still recent default experience highlights the cyclical nature of default rates and marks the end of the benign credit cycle of most of the 1990s.
} 
mirrored the distribution of losses of the bonds in each rating class for which we did have loss data. Finally, there were over 100 bonds that were unrated and which we had no price data. We placed them in the unrated category (see Table 1). Since we are only looking at the relative loss experience for rated bonds, these unrated bonds played no further part in our study.

We then applied a number of models to calculate unexpected loss rates (or "economic"

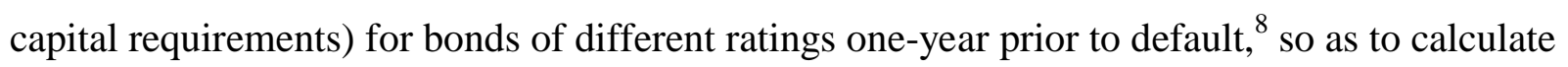
loss rates at various confidence intervals. Three distribution models were used to initially calculate loss rates; (i) a normal distribution (ii) the actual distribution and (iii) a Poisson distribution (with a stable mean). The first two models are similar to those used in JP Morgan's CreditMetrics $^{\circledR}$ and the third is a simplified version of the model assumed in CSFP's CreditRisk $^{+}$. Tables 4-9 show the results for the full sample period for rating classes A through $\mathrm{CCC}$ and below. Note that BIS bucket 2 is represented here by the ratings $\mathrm{A}, \mathrm{BBB}, \mathrm{BB}$ and $\mathrm{B}$ and bucket 3 is represented by the CCC and lower category. Bucket 1 is not shown because of non-existent defaults in the AAA to AA ratings range at one year prior to default.

In addition, we carried out a set of Monte-Carlo simulations. Since most formal credit-

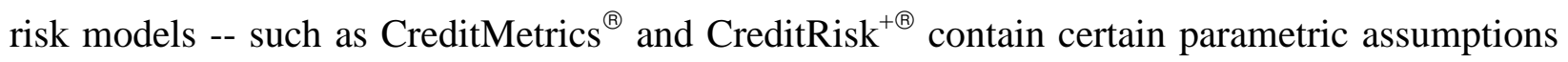
(e.g., about correlations) embedded in their structures, these formal models' results reflect, in part, these untested assumptions. Monte-Carlo simulations, by contrast, allow estimation of the size of losses in the tail of loan loss distributions conditional only on assumptions made about the composition of bank portfolios. In the simulations, we follow Carey (1998) and look at a number of portfolios. The first reflects the allocation for US life insurance company privately placed bonds. In this allocation, approximately $13 \%$ are below investment grade. The second reflects the

\footnotetext{
${ }^{8}$ The one-year horizon is consistent with the horizon adopted by most internal credit risk models.
} 
suggested allocation by Carey for US banks commercial loan portfolios. This reflects, on average, a much lower credit quality than that adopted by life insurers, with some $50 \%$ being below investment grade. In addition to these two portfolios, we look at loss distributions for portfolios that contain respectively only AAA, AA and A bonds (portfolio 3), BBB bonds (portfolio 4), BB bonds (portfolio 5), B bonds (portfolio 6) and CCC and lower (portfolio 7).

In conducting the Monte-Carlo simulation, a portfolio aggregate size is chosen (here $(\$ 1$ billion) and assets are drawn at random subject to the composition of the portfolios conforming to the representative portfolios discussed above (until the target aggregate portfolio size is reached). The loss rate on the portfolio is then calculated. For each portfolio (1 to 7 ) the simulation is repeated 50,000 times and the frequency distribution of losses forms an estimate of the relevant loss distribution. From that loss distribution, loss rates at different quantiles can be analyzed, and by implication the capital reserves needed to absorb the level of unexpected losses are determined. Unexpected losses are the difference between the loss rate at a given quantile and the mean, or expected, loss rate.

\subsection{Empirical Results of Loss Distributions}

Table 4 shows that, for A-rated bonds, 12,115 issuers did not default over this period, while seven (7) A rated issuers defaulted within one year of being rated A. Of the seven, two defaults had a loss rate in the $1 \%$ to $10 \%$ range, two had loss rates in the $11 \%$ to $20 \%$ range, two had loss rates in the $21 \%$ to $30 \%$ range and one had a loss rate in the $51 \%$ to $60 \%$ range. The mean loss rate (the expected loan loss reserve) for the entire A-rated sample was $.012 \%$. Recall, we do not observe any one year losses for AAA or AA rated bonds; hence, no tables are presented. 
For capital or unexpected loss calculations, different quantiles were used to describe extreme losses. The more conservative the banker or the regulator, the higher the quantile chosen. For the normal distribution, we calculated the $95 \%(1.64485 \sigma), 99 \%(2.32634 \sigma)$ and $99.97(3.431925 \sigma)$ unexpected loss rates. As can be seen for single A bonds, these unexpected loss rates were respectively $1.021 \%, 1.448 \%$ and $2.142 \%$. These are well below the current $8 \%$ capital requirement (actually quite close to the proposed guideline for AAA/AA credits). However, as is well known, the loss distribution of loans is highly non-normal, so the second calculation, also shown in Table 4, uses the actual distribution of bond losses. To calculate a particular quantile's loss rate involves counting backwards under the actual default distribution and finding the loss rate coincident with the default that just matches the quantile. For example, to find the unexpected loss rate consistent with the $99.97 \%$ quantile (i.e., where capital is sufficiently large to meet all but 3 losses out of $10,00(9)$, we calculate that $.03 \%$ of 12,122 is 3.6 issuers. We then count backwards under the A-rated bond distribution and find that 3.6 defaults are coincident with a loss range of $11 \%$ to $20 \%$. In all cases, we take the mid-point of the loss range (here 15\%) to reflect the unexpected loss. To net out the loan loss reserve, we deduct from $15 \%$ the expected or mean loss rate (here $.012 \%$ ) to get an unexpected loss rate at the $99.97 \%$ quantile of $14.988 \%$. This is clearly much larger than the current $8 \%$ ratio of the BIS. Note, however, at the less conservative quantiles of $99 \%$ and $95 \%$, the unexpected loss rates (and hence capital ratios) are actually zero.

\footnotetext{
${ }^{9}$ Alternatively, where the bank will have sufficient capital to survive all but 3 years out of the next 10,000 years.
} 
Table 4 carries out a similar exercise to the one discussed above for $\mathrm{BBB}, \mathrm{BB}, \mathrm{B}$ and CCC (and lower) bonds. In addition, a "total" column aggregates across all of the rating classes.

We can use these calculations to examine the degree of homogeneity (heterogeneity) across the four rating grades $\mathrm{A}, \mathrm{BBB}, \mathrm{BB}$ and $\mathrm{B}$ entering into bucket 2 . Using the $99^{\text {th }}$ percentile, or its equivalent, as a standard for comparison, we can see that, under the normal distribution assumption, the capital requirements for the four ratings classes are respectively $1.448 \%$, $2.323 \%, 7.102 \%$ and $17.030 \%$. Even under the highly unrealistic assumption of normally distributed loss rates, B rated bonds' risk is more than 10 times that of A rated bonds. ${ }^{\text {Looking }}$ at the actual distribution of losses at the $99^{\text {th }}$ percentile, a similar degree of heterogeneity emerges. Specifically, the capital requirements are respectively $0 \%, 0 \%, 4.7 \%$ and $43.266 \%$, indicating a very clear distinction between unexpected loss rates of investment grade borrowers (those rated $\mathrm{A}$ and $\mathrm{BBB}$ ) and below investment grade borrowers (those rate $\mathrm{BB}$ and $\mathrm{B}$ ). Thus, Table 4 suggests that if we use external rating agency buckets, as the current proposal suggests, for capital requirement risk-weights, the degree of granularity is far too coarse.

Finally, what can be said about the relative risk weightings of buckets 2 and 3 . Under the BIS proposal, bucket 2 has a 100\% risk-weight while bucket 3 has a $150 \%$ risk weight implying that loans in bucket 3 are $1 \frac{1}{2}$ times "more default risky" than those in bucket 2 . As can be seen from Table 4, even where we use, for bucket 2, the lowest rating grade (B), and unexpected loss rates are used to compare with bucket 3 loss rates, the normal distribution

\footnotetext{
${ }^{10}$ Interestingly, the total mean or expected loss rate of $0.598 \%$ is quite close to the level of banks' average loan loss reserve holdings in recent years.

${ }^{11}$ This compares to an expected loss rate ratio of about 100 times greater for B vs. A rated bonds (see the cumulative loss rates in Altman, etal. (1999). For example, the five year cumulative loss rate for bonds rated A upon issuance is $0.12 \%$, while the B rated bonds' loss rate is $13.9 \%$. The fifth year's marginal (one year) loss rate is $0.04 \%$ for A rated bonds compared to $3.36 \%$ for B rated bonds.
} 
suggests a risk-weighting ratio of 3.2 times (i.e., $55.455 \%$ divided by $17.030 \%$ ) at the $99 \%$ level. The equivalent $99 \%$ relative risk-weighting was 1.64 times using the actual distribution. Of course, these relative risk-weightings are far larger when either $\mathrm{A}, \mathrm{BBB}$, or $\mathrm{BB}$ are used to compare to loss rates in bucket 3. Overall, these results suggests that for the new BIS proposal, the degree of a loan's credit risk in bucket 3 may be relatively underpriced (under capitalized) to the that of a loan in bucket 2 .

\subsection{Robustness Checks}

We decided to carry out a number of additional robustness checks to examine how the degree of heterogeneity in bucket 2 changes under "alternative" assumptions. In Table 5, we recognize that Table 4's findings are biased towards finding higher capital ratios and may be confounding loan losses with bond losses (the latter is what we actually measure). Both biases occur, in part, because for non-defaulters we have used the number of issuers (i.e., implicitly assuming one bond per issuer), while the defaults reflect the number of defaulted issues (i.e., one issuer may default on a number of bonds) $\frac{12}{12}$ This bias is corrected in Table 5 where we only analyze the loss rate on the most senior bond or note of each defaulting issuer. As a result, the total number of defaults falls from 692 to $334{ }^{13}$ This has the additional advantage of making bonds look more like loans, since most bank loans have covenants and/or collateral backing that make them highly senior in the debt repayment structure-especially on default.

Again we find a considerable degree of heterogeneity persisting. For example, at the $99 \%$ quantile $(2.3264 \sigma)$, and assuming the normal distribution, the unexpected loss rates vary widely: i.e., $0.446 \%$ (A), $5.619 \%$ (BBB), $8.306 \%$ (BB), 24.694\% (B). At the same $99 \%$ percent quantile,

\footnotetext{
${ }^{12}$ The rating agencies only report the number of issuers for each grade rating category in each of the years in our sample period. See, for example, Table 16 in S\&P (1999).

${ }^{13}$ The most senior bond is defined as the one with the highest price one-year prior to default.
} 
under the actual distribution, the unexpected loss rates are respectively $0 \%, 0 \%, 0 \%$, and $72.874 \%$.

Table 6 repeats a similar exercise as Table 5 but assumes defaults follow a Poisson distribution with a stable mean. ${ }^{14}$ For bucket 2 , the simple Poisson model produces similar results as those in Tables 4 and 5. In particular, the unexpected loss rates at the $99 \%$ quantile are respectively: 0\%(A), 0\%(BBB), 0.205\% (BB) and $17.011 \%(B)$.

Finally, Table 7 repeats a similar exercise to those above except that it replaces the number of issuers in the no default category with an estimate of the number of issues. 15 This considerably increases the number of non-defaults and reduces the mean or expected loss rate. The unexpected loss rates are also affected because of the larger total sample size. As can be seen from Table 7, however, using estimated issues instead of issuers for the non-defaulting class leaves the basic conclusions unchanged. Specifically, again using the $99^{\text {th }}$ percent quantile, the unexpected loss rate under the normal distribution is $0.604 \%$ for A rated borrowers versus $9.550 \%$ for $\mathrm{B}$ rated borrowers, while using the actual distribution the relative unexpected loss rates for $\mathrm{A}$ versus $\mathrm{B}$ are respectively $0 \%$ versus $33.912 \%$. Table 8 shows a similar "lack of granularity" using the Poisson distribution. In this case $0 \%$ versus $8.704 \%$.

\footnotetext{
${ }^{14}$ The CreditRisk $^{+®}$ model assumes defaults follow a Poisson distribution around a shifting mean. Specifically, the mean default rate is assumed to follow a gamma distribution. The Poisson distribution is a simple distribution in that its mean equals its variance. Assuming a stable mean will tend to underestimate the "fat-tailedness" of the distribution and thus unexpected loss rates will be understated.

${ }^{15}$ This was done by taking three monthly samples (for December 1987, December 1992 and February 1999) on the number of issues per issuer from $\mathrm{S}$ and $\mathrm{P}$ bond guides, calculating an average number of issues per defaulting issuer in each rating category and multiplying the number of issuers row in Table 1 by the resulting average number of issues per issuer.

${ }^{16}$ Similar conclusions, regarding the relative risk weights of buckets 2 and 3 , to those discussed earlier are also reached by analyzing Tables 5 through 8 . The large risk weighting differences between rating classes (and lower) are particularly evident.
} 


\subsection{Simulation Results}

Table 9 looks at the loss rates generated from Monte-Carlo simulations of the seven different portfolios discussed earlier (US life insurer-type portfolio, US bank-type portfolio, and different agency ratings). Each loss distribution is based on 50,000 simulations and an aggregate portfolio size of $\$ 1$ billion. In recent years, $\$ 1$ billion in asset size has been viewed as representative of medium-sized US banks. ${ }^{\square}$

From Table 9, it can be seen that at the 99\% quantile, the unexpected loss rates suggest capital requirements much lower than $8 \%$ in all cases, even the most risky rating class. For the insurance company portfolio (portfolio 1), the unexpected loss rate (99\% loss rate minus the mean loss rate) suggests a capital ratio of $0.673 \%-0.109 \%=0.564 \%$. For the riskier bank loan portfolio (portfolio 2), the implied capital ratio is $1.077 \%$. Looking at the question of bucket homogeneity, which is the key focus of this paper, it can be seen that unexpected loss rates for BBB vs. BB vs. B differ significantly, i.e., specifically, $0.235 \%$ vs. $0.769 \%$ vs. $1.765 \%$. 18 The simulation results clearly show that the unexpected loss rate of the investment grade components (A and $\mathrm{BBB}$ ) of bucket 2 is much lower than the below investment grade components of bucket 2 (BB and B). Even for the CCC and lower portfolio (bucket 3) the unexpected loss rate is $15.2 \%$ $-10.119 \%=5.08 \%$. This may imply that the suggested BIS capital ratio for bucket $3(12 \%)$ is

\footnotetext{
${ }^{17}$ Interestingly, the results of our simulations were quite insensitive to asset portfolio size assumptions beyond the $\$ 1$ billion size range.

${ }^{18}$ In this test, A was combined with AA and AAA to be comparable with the Carey (1998) paper.
} 
perhaps too high. 19 Overall, the Monte-Carlo simulations confirm the results of the parametric approaches discussed in Tables 4-8 -- especially the heterogeneity of bucket 2.

\subsection{Summary and Proposal}

This paper has examined two specific aspects of stage 1 of the BIS's proposed reforms to the risk-based capital ratio. It has been argued that relying on "traditional" agency ratings could produce cyclically lagging rather leading capital requirements, resulting in an enhanced rather than reduced degree of instability in the banking and financial system. In addition, even if riskweights were to be tied to traditional agency ratings, the current bucketing proposal lacks a sufficient degree of granularity. In particular, lumping A and BBB (investment grade borrowers) together with BB and B (below investment grade borrowers) severely misprices risk within that bucket and calls, at a minimum, for that bucket to be split into two.

Table 10 repeats the calculations of Table 5, but groups together $\mathrm{A}$ and $\mathrm{BBB}$ for comparison with $\mathrm{BB}$ and $\mathrm{B}$. If we take the most conservative regulatory view and require capital to be sufficient to meet the $99.97 \%$ quantile test, then we can calculate some relative riskweightings as examples for a split bucket 2. Specifically, in Table 10, which is based on senior bond defaults, (the bond default data that most closely resembles loans), we observe 14 defaults out of 19,658 observations in the A/BBB investment grade bucket and 227 out of 10,535 in the non-investment grade BB/B bucket within the one-year time horizon. At the $99.97 \%$ level, for the actual distribution results, the ratio of unexpected losses between the two buckets is 1.65 (90.846/54.96). Under the normal distribution assumption for all levels of confidence (95\% to

\footnotetext{
${ }^{19}$ This assumes that appropriate reserves for the high expected losses (e.g., over 10\%) are deducted from the profit and loss accounts.
} 
99.97\%), the ratio is about 5.4 (e.g., $28.240 / 5.208$ for $3.43 \sigma$ or the $99.97 \%$ quantile). ${ }^{20}$ Hence, we find a considerable difference in risk between these buckets, as expected. The CCC and lower bucket is considerably more risky under the normal distribution assumption - about 2.5 times the BB/B bucket. ${ }^{2-1}$ Since the CCC and lower category has so few observations (387), we cannot be as confident as we would like to be about its exact risk compared to other buckets.

\section{1 $\quad$ A Revised Bucket Proposal}

A bucket system with four categories, and with a weighting system something like that shown in Table 11, would accomplish much of what the BIS proposal is attempting to do, and also comes closer to capturing the reality of actual relative default losses by ratings.

We constructed this Table based on the following logic. We felt constrained to choose a non-zero weighting for the first bucket (AAA/AA), although our results (over the last 19 years) clearly show that no defaults have actually taken place within one year for bonds in these two highest ratings. The choice of $10 \%$ for bucket 1 is therefore arbitrary but still less than the BIS proposal's $20 \%$. A second consideration was that we felt it appropriate to give the new $\mathrm{BB} / \mathrm{B}$ non-investment grade bucket a full $100 \%$ weighting. This left us with a decision as to the appropriate $\mathrm{A} / \mathrm{BBB}$ classification. We decided to use a ratio of about 3.33 to 1 when comparing the $\mathrm{BB} / \mathrm{B}$ bucket with this $\mathrm{A} / \mathrm{BBB}$ bucket. This is about the midpoint between the normal distribution and actual distribution's results at the $99.97 \%$ quantile (1.65 and 5.40), Hence, the designation of $30 \%$ for our bucket 2 . Note that this $30 \%$ weighting is considerably lower than the

\footnotetext{
${ }^{20}$ The $99.97 \%$ level is actually not shown but is essentially identical to the $99.9 \%$ level.

${ }^{21}$ The results for the $\mathrm{CCC}$ and lower bucket was about the same as the BB/B for the actual distribution, since both were near the maximum loss possible at the $99.97 \%$ level.

22 One could actually argue for a higher weighting in this bucket but this would almost surely cutoff most lending to firms in this bucket --- a bucket which we believe now represents a very high proportion of current loans outstanding.
} 
BIS proposal and the $100 \%$ weighting for bucket 3 is the same as their earlier proposal. Finally, we adopt the same $150 \%$ weighting for below B- credits (bucket 4 ).

\subsection{The Unrated Class}

Note that we do not propose any specific weighting for the category "unrated." We feel that the appropriate weighting system that bank regulators sanction will be based on a combination of external and internal ratings. Using internal ratings obviates the need for an "unrated" class since banks should be rating all customers. Also, the currently proposed BIS unrated class is essentially a classification that assumes no clear risk analysis. That is not very helpful in a world where most assets are unrated by external rating agencies; hence, the inevitable sanctioning of internal systems.

\subsection{Final Comment}

We are aware that our proposals are not prefect, but they appear to resemble more closely the existing data on unexpected losses. Although we do not expect regulatory capital arbitrage to cease completely, we are convinced that it will be reduced with our modifications and will bring regulatory capital closer to economic capital estimates. 


\section{References}

1. Altman, E.I., "Measuring Corporate Bond Mortality and Performance" Journal of Finance, Vol. XLIV, No. 4, September 1989, 909-922.

2. Altman, E.I. and a. Saunders, "Credit Risk Measurement: Developments Over the Last 20 Years," Journal of Banking \& Finance, Vol. 21, No. 11, 1997, 1721-1742.

3. Altman, E.I., D. Cooke and V. Kishore, "Defaults and Returns on High Yield Bonds: Analysis through 1998 \& Default Outlook for 1999-2001, NYU Salomon Center Special Report, January 1999, updated in January 2000.

4. Balse Committee on Banking Supervision "Credit Risk Modeling: Current Practices and Applications," Basle, April 1999.

5. Basle Committee on Banking Supervision, “A New Capital Adequacy Framework, Basle, June 1999.

6. Basel Committee on Banking Supervision, "Range of Practice in Banks" Internal Ratings Systems, Basel, January 2000.

7. Carey, M., "Credit Risk in Private Debt Portfolios," Journal of Finance, August 1998, pp. 1363-1387.

8. Caouette, J.B., E.I. Altman and P. Narayanan, Managing Credit Risk: The Next Great Financial Challenge, John Wiley \& Sons, New York, 1998.

9. CreditMetrics, J.P. Morgan, April 1997.

10. Credit Suisse Financial Products, “Credit Risk ${ }^{+}$: A Credit Risk Measurement Framework," London, 1997.

11. Jonsson J.G. and M. Fridson "Forecasting Default Rates on High Yield Bonds, Journal of Fixed Income, June 1996.

12. Moody's "Predicting Default Rates: A Forecasting Model for Moody's Issuer-Based Default Rates," Special Comment, Global Credit Research, August 1999.

13. Saunders, A., Credit Risk Measurement, "New Approaches to Value at Risk and Other Paradigms, John Wiley \& Sons, New York, 1999.

14. Standard \& Poor's, "Rating Performance 1998: Stability \& Transition," S\&P Special Report, March 1999.

15. Treacy, W. and M. Carey, "Credit Rating Systems at large US Banks" Federal Reserve Bulletin, November 1998, and Journal of Banking \& Finance, 24, 2000, 24, 167-201. 
TABLE 1

Proposal BIS Risk Weighting System for Bank Loan Credits

\begin{tabular}{|c|c|c|c|c|c|c|c|}
\hline \multirow[t]{2}{*}{ Claim } & & \multicolumn{6}{|c|}{ Assessment } \\
\hline & & $\begin{array}{l}\text { AAA to } \\
\text { AA- }\end{array}$ & $\mathrm{A}+$ to $\mathrm{A}-$ & $\begin{array}{l}\text { BBB+ to } \\
\text { BBB- }\end{array}$ & $\mathrm{BB}+$ to $\mathrm{B}-$ & Below B- & Unrated \\
\hline Sovereigns & & $0 \%$ & $20 \%$ & $50 \%$ & $100 \%$ & $150 \%$ & $100 \%$ \\
\hline \multirow{2}{*}{ Banks } & Option $1^{1}$ & $20 \%$ & $50 \%$ & $100 \%$ & $100 \%$ & $150 \%$ & $100 \%$ \\
\hline & Option $2^{2}$ & $20 \%$ & $50 \%$ & $50 \%^{3}$ & $100 \%^{3}$ & $150 \%$ & $50 \%^{3}$ \\
\hline Corporates & & $20 \%$ & $100 \%$ & $100 \%$ & $100 \%$ & $150 \%$ & $100 \%$ \\
\hline
\end{tabular}

${ }^{1}$ Risk weighting based on risk weighting of sovereign in which the bank is incorporated.

${ }^{2}$ Risk weighting based on the assessment of the individual bank.

${ }^{3}$ Claims on banks of a short original maturity, for example less than six months, would receive a weighting that is one category more favorable than the usual risk weight on the 
TABLE 2

Rating Agencies Extreme Credit Quality Categories

\begin{tabular}{|l|l|l|}
\hline Credit Assessment Institution & Very High Quality Assessment & Very Low Quality Assessment \\
\hline Fitch IBCA & AA- and above & Bellow B- \\
\hline Moody's & Aa3 and above & Below B3 \\
\hline Standard \& Poor's & AA- and above & Below B- \\
\hline Export insurance agencies & 1 & 7 \\
\hline
\end{tabular}

Source: Basel Committee on Bank Supervision (June 1999). 
TABLE 3

ANNUAL RETURNS, YIELDS AND SPREADS

ON TEN-YEAR TREASURY (TREAS)

AND HIGH YIELD (HY) BONDS*

(1978-1999)

RETURN(\%)

\begin{tabular}{|c|c|c|}
\hline YEAR & HY & TREAS \\
\hline 1999 & 1.73 & (8.41) \\
\hline 1998 & 4.04 & 12.7 \\
\hline 1997 & 14.27 & 11. \\
\hline 1996 & 11.24 & 0. \\
\hline 1995 & 22.40 & 23. \\
\hline 1994 & (2.55) & (8.2 \\
\hline 1993 & 18.33 & 12. \\
\hline 1992 & 18.29 & 6. \\
\hline 1991 & 43.23 & 17.1 \\
\hline 1990 & $(8.46)$ & \\
\hline 1989 & 1.98 & 16.72 \\
\hline 1988 & 15.25 & 6. \\
\hline 1987 & 4.57 & (2.67) \\
\hline 1986 & 16.50 & 24.0 \\
\hline 1985 & 26.08 & 31.5 \\
\hline 1984 & 8.50 & 14.8 \\
\hline 1983 & 21.80 & 2.2 \\
\hline 1982 & 32.45 & 42.08 \\
\hline 1981 & 7.56 & 0.4 \\
\hline 1980 & (1.00) & $(2.96$ \\
\hline 1979 & 3.69 & $(0.86$ \\
\hline 1978 & 7.57 & $(\mathbf{1 . 1 1}$ \\
\hline
\end{tabular}

PROMISED YIELD $(\%)$
HY TREAS SPREAD

HY TREAS SPREAD

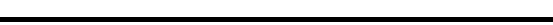

10.14

(8.73)

3.11

11.20

(1.18)

5.74

6.25

11.79

26.05

(15.34)

(14.74)

8.91

7.24

(7.58)

(5.46)

(6.32)

19.57

(9.63)

7.08

1.96

4.55

8.68

0.04

10.04
9.20

9.58

9.76

11.50

9.08

10.44

12.56

18.57

15.17

13.70

13.89

12.67

13.50

14.97

15.74

17.84

15.97

13.46

12.07

10.92

6.44

4.65

5.75

6.42

5.58

7.83

5.80

6.69

6.70

8.07

7.93

9.15

8.83

7.21

8.99

11.87

10.70

13.86

12.08

10.23

9.13

8.11
4.97

5.39

3.45

3.16

4.18

3.67

3.28

3.75

5.86

10.50

7.24

4.55

5.06

5.46

4.51

3.10

5.04

3.98

3.89

3.23

2.94

2.81

ARITHMETIC ANNUAL AVERAGE:

1978-1999

$$
12.16
$$

9.28

2.88

12.82

8.27

COMPOUND ANNUAL AVERAGE:

\begin{tabular}{|llll|}
\hline $1978-1999$ & 11.54 & 8.58 & 2.96 \\
\hline
\end{tabular}

*End of year yields.

Source: Salomon Smith Barney Inc.'s High Yield Composite Index; Altman et al (2000). 
Table 4

FREQUENCY DISTRIBUTION OF LOSSES

(PRINCIPAL AND COUPON), (1981 - 9/1999)

BY RATING ONE YEAR BEFORE DEFAULT

(NORMAL AND ACTUAL LOSS DISTRIBUTIONS)

\begin{tabular}{|c|c|c|c|c|c|c|c|c|c|c|c|c|c|}
\hline $\begin{array}{c}\text { Range of } \\
\text { Default Losses }\end{array}$ & Midpoint & $\mathbf{A}$ & & BBB & & BB & & B & & C \& Lower & & Total & \\
\hline 0 & 0 & 12115 & & 7529 & & 5311 & & 4997 & & 294 & & 30246 & \\
\hline $0.01-0.10$ & 0.05 & 2 & & 26 & & 11 & & 81 & & 43 & & 163 & \\
\hline $0.11-0.20$ & 0.15 & 2 & & 16 & & 15 & & 89 & & 18 & & 140 & \\
\hline $0.21-0.30$ & 0.25 & 2 & & 4 & & 18 & & 81 & & 36 & & 141 & \\
\hline $0.31-0.40$ & 0.35 & 0 & & 1 & & 8 & & 62 & & 24 & & 95 & \\
\hline $0.41-0.50$ & 0.45 & 0 & & 0 & & 8 & & 29 & & 24 & & 61 & \\
\hline $0.51-.060$ & 0.55 & 1 & & 0 & & 3 & & 17 & & 18 & & 39 & \\
\hline $0.61-0.70$ & 0.65 & 0 & & 0 & & 1 & & 10 & & 21 & & 32 & \\
\hline $0.71-0.80$ & 0.75 & 0 & & 0 & & 0 & & 2 & & 5 & & 7 & \\
\hline $0.81-0.90$ & 0.85 & 0 & & 0 & & 0 & & 4 & & 6 & & 10 & \\
\hline $0.91-0.94$ & 0.92 & 0 & & 0 & & 0 & & 0 & & 0 & & 0 & \\
\hline $0.95-0.98$ & 0.96 & 0 & & 0 & & 0 & & 0 & & 1 & & 1 & \\
\hline 0.99 & 0.99 & 0 & & 0 & & 0 & & 0 & & 0 & & 0 & \\
\hline 1 & 1 & 0 & & 0 & & 0 & & 0 & & 3 & & 3 & \\
\hline Total & & 12122 & & 7576 & & 5375 & & 5372 & & 493 & & 30938 & \\
\hline Mean & & $0.012 \%$ & & $0.067 \%$ & & $0.298 \%$ & & $1.734 \%$ & & $14.079 \%$ & & $0.598 \%$ & \\
\hline Median & & $0.000 \%$ & & $\mathbf{0 . 0 0 0 \%}$ & & $0.000 \%$ & & $0.000 \%$ & & $0.000 \%$ & & $0.000 \%$ & \\
\hline St.Dev & & $0.628 \%$ & & $1.027 \%$ & & $3.181 \%$ & & $8.066 \%$ & & $29.890 \%$ & & $5.001 \%$ & \\
\hline 3.43192sigma-E(L) & & $2.142 \%$ & & $3.458 \%$ & & $10.619 \%$ & & $25.947 \%$ & & $\mathbf{8 8 . 5 0 1 \%}$ & & $16.566 \%$ & \\
\hline 2.32634sigma-E(L) & & $1.448 \%$ & & $2.323 \%$ & & $7.102 \%$ & & $17.030 \%$ & & $55.455 \%$ & & $11.037 \%$ & \\
\hline 1.64485sigma-E(L) & & $1.021 \%$ & & $1.623 \%$ & & $2.051 \%$ & & $11.533 \%$ & & $35.085 \%$ & & $7.628 \%$ & \\
\hline $99.97 \%$ & & $14.988 \%$ & 3.6 & $24.933 \%$ & 2.3 & $54.702 \%$ & 1.6 & $83.266 \%$ & 1.6 & $85.921 \%$ & 0.1 & $84.402 \%$ & 9.3 \\
\hline $99.00 \%$ & & $0.000 \%$ & 121.2 & $0.000 \%$ & 75.8 & $4.702 \%$ & 53.8 & $43.266 \%$ & 53.7 & $70.921 \%$ & 4.9 & $24.402 \%$ & 309.4 \\
\hline $95.00 \%$ & & $0.000 \%$ & 606.1 & $0.000 \%$ & 378.8 & $0.000 \%$ & 268.8 & $13.266 \%$ & 268.6 & $50.921 \%$ & 24.7 & $0.000 \%$ & 1546.9 \\
\hline
\end{tabular}

Source: Standard \& Poor's NYU Salomon Center Default Data Base 
Table 5

FREQUENCY DISTRIBUTION OF LOSSES

(PRINCIPLE AND COUPON), (1981 - 9/1999)

BY RATING ONE YEAR BEFORE DEFAULT

(NORMAL AND ACTUAL LOSS DISTRIBUTIONS) (Based on Number of Issuers)

$\begin{array}{cc}\begin{array}{c}\text { Range of } \\ \text { Default Losses }\end{array} & \text { Midpoin } \\ 0 & 0 \\ 0.01-0.10 & 0.05 \\ 0.11-0.20 & 0.15 \\ 0.21-0.30 & 0.25 \\ 0.31-0.40 & 0.35 \\ 0.41-0.50 & 0.45 \\ 0.51-0.60 & 0.55 \\ 0.61-0.70 & 0.65 \\ 0.71-0.80 & 0.75 \\ 0.81-0.90 & 0.85 \\ 0.91-0.94 & 0.92 \\ 0.95-0.98 & 0.96 \\ 0.99 & 0.99 \\ 1\end{array}$

$\begin{array}{ccc}\text { BBB } & \text { BB } & \text { B } \\ 7529 & 5311 & 4997 \\ 0 & 0 & 14 \\ 1 & 0 & 11 \\ 1 & 1 & 18 \\ 1 & 5 & 19 \\ 1 & 2 & 22 \\ 3 & 3 & 32 \\ 0 & 3 & 33 \\ 4 & 1 & 28 \\ 0 & 1 & 19 \\ 0 & 2 & 11 \\ 0 & 1 & 1 \\ 1 & 0 & 0 \\ 0 & 0 & 0\end{array}$

CCC \& Lower

Total

997

30246

Total Default

2

12

19

208

12115

7529

5311

4997

334

12117

7541

5330

5205

93

30246

30580

Mean
Median
St.Dev
3.43192sigma-E(L)
2.32634sigma-E(L)
1.64485sigma-E(L)
$\quad 99.97 \%$
$\quad 99.00 \%$
$\quad 95.00 \%$

$\begin{array}{ll}\mathbf{0 . 0 0 2 \%} & \\ \mathbf{0 . 0 0 0 \%} & \\ \mathbf{0 . 1 9 3 \%} & \\ \mathbf{0 . 6 5 9 \%} & \\ \mathbf{0 . 4 4 6 \%} & \\ \mathbf{0 . 3 1 4 \%} & \\ \mathbf{0 . 0 0 0 \%} & \mathbf{3 . 6} \\ \mathbf{0 . 0 0 0 \%} & \mathbf{1 2 1 . 2} \\ \mathbf{0 . 0 0 0 \%} & \mathbf{6 0 5 . 9}\end{array}$

$\mathbf{0 . 0 9 1 \%}$
$\mathbf{0 . 0 0 0 \%}$
$\mathbf{2 . 4 5 4 \%}$
$\mathbf{8 . 3 3 2 \%}$
$\mathbf{5 . 6 1 9 \%}$
$\mathbf{3 . 9 4 6 \%}$
$\mathbf{7 4 . 9 0 9 \%}$
$\mathbf{0 . 0 0 0 \%}$
$\mathbf{0 . 0 0 0 \%}$

$\mathbf{0 . 2 0 5 \%}$

$\mathbf{0 . 0 0 0 \%}$

$\begin{array}{lll}\mathbf{2 . 4 5 4 \%} & \mathbf{3 . 6 5 8 \%} & \mathbf{1 1 . 5 2 9 \%}\end{array}$

$12.351 \%$

$0.000 \%$

$0.000 \%$

$37.440 \%$

$\mathbf{8 . 3 0 6 \%}$

$\mathbf{2 4 . 6 9 4 \%}$

$\mathbf{5 . 8 1 3 \%}$

$2.3 \quad 91.795 \%$

$16.837 \%$

$75.4 \quad 0.000 \%$

$377.1 \quad 0.000 \%$

$\mathbf{8 9 . 8 7 4 \%}$

$\mathbf{7 2 . 8 7 4 \%}$

$0.000 \%$ 
Table 6

FREQUENCY DISTRIBUTION OF LOSSES

(PRINCIPLE AND COUPON), (1981 - 9/1999)

BY RATING ONE YEAR BEFORE DEFAULT

(NORMAL AND ACTUAL LOSS DISTRIBUTIONS)

(Based on Number of Issuers) - Poisson Process for Defaults

\section{Range of Midpoint A \\ A}

Default Losses

$\begin{array}{cc}0 & 0 \\ 0.01-0.10 & 0.05 \\ 0.11-0.20 & 0.15 \\ 0.21-0.30 & 0.25 \\ 0.31-0.40 & 0.35 \\ 0.41-0.50 & 0.45 \\ 0.51-0.60 & 0.55 \\ 0.61-0.70 & 0.65 \\ 0.71-0.80 & 0.75 \\ 0.81-0.90 & 0.85 \\ 0.91-0.94 & 0.92 \\ 0.95-0.98 & 0.96 \\ 0.99 & 0.99 \\ 1 & 1\end{array}$

Total Default

Total Non-Default

Total

Mean

Median

St.Dev

$\mathbf{9 9 . 9 7 \%}$

$\mathbf{9 9 . 0 0 \%}$

$95.00 \%$

default rate $\mathrm{m}$ per 100

loans in the portfolio

12115
0
2
0
0
0
0
0
0
0
0
0
0
0

2

12115

12117

$\mathbf{0 . 0 0 2 \%}$

$\mathbf{0 . 0 0 0 \%}$

$\mathbf{0 . 1 9 3 \%}$

$\mathbf{0 . 0 0 0 \%}$

$\mathbf{0 . 0 0 0 \%}$

$0.000 \%$

0.017

BBB
7529
0
1
1
1
1
3
0
4
0
0
0
1
0

7541

$\mathbf{0 . 0 9 1 \%}$

$\mathbf{0 . 0 0 0 \%}$

$\mathbf{2 . 4 5 4 \%}$

$\mathbf{0 . 0 9 1 \%}$

$\mathbf{0 . 0 0 0 \%}$

$0.000 \%$

0.159

$\mathbf{9 9 . 9 9 7 \%}$

$\mathbf{9 9 . 1 7 8 \%}$

$\mathbf{9 9 . 1 7 8 \%}$
$99.194 \%$

$\mathbf{9 9 . 1 9 4 \%}$

Sources: Standard \& Poor's NYU Salomon Center Default Data Base.

BB

5311

0

0

1

5

2

3

3

1

2

1

0

19

5311

5330

\section{B}

4997

208

4997

5205

$2.126 \%$

$0.000 \%$

$\mathbf{1 1 . 5 2 9 \%}$

$\mathbf{0 . 0 0 0 \%}$

$\mathbf{3 . 6 5 8 \%}$

$23.391 \%$

$17.011 \%$

$12.759 \%$

3.996

$0.000 \%$

0.356

$\mathbf{9 9 . 9 4 9 \%}$

$\mathbf{9 9 . 4 2 1 \%}$

$\mathbf{9 4 . 9 7 2 \%}$

$\begin{array}{cc}\text { CCC \& Lower } & \text { Total } \\ & \\ 294 & 30246 \\ 4 & 18 \\ 8 & 22 \\ 11 & 31 \\ 11 & 36 \\ 11 & 36 \\ 9 & 47 \\ 17 & 53 \\ 12 & 45 \\ 7 & 27 \\ 1 & 14 \\ 2 & 4 \\ 0 & 1 \\ 0 & 0\end{array}$

334

30246

30580

$\mathbf{0 . 5 7 4 \%}$

$\mathbf{0 . 0 0 0 \%}$

$\mathbf{6 . 0 2 8 \%}$

$2.869 \%$

$1.721 \%$

$1.148 \%$

1.092

$99.976 \%$

$\mathbf{9 9 . 6 7 1 \%}$

$96.975 \%$ $\mathbf{2 4 . 5 2 1 \%}$

495.178\%

$374.403 \%$

24.031

$99.979 \%$

$\mathbf{9 9 . 1 8 2 \%}$

96.454\%
6
4
3


$9.979 \%$
$9.001 \%$

$\mathbf{9 4 . 9 2 1 \%}$ 
Table 7

FREQUENCY DISTRIBUTION OF LOSSES

(PRINCIPLE AND COUPON), (1981 - 9/1999) 1 YEAR BEFORE DEFAULT

BY RATING ONE YEAR BEFORE DEFAULT

(NORMAL AND ACTUAL LOSS DISTRIBUTIONS)

(Based on Number of issues)

Range of Mid point
Default of Losses

A

BBB

BB

B

CCC \& Lower

Total

$\begin{array}{ccc}0 & 0 & 67507\end{array}$

34525

12137

8187

$0.01-0.10$

0.05
0.15

$0.21-0.30$

$0.31-0.40$

$0.41-0.50$

$0.51-0.60$

$0.61-0.70$

$0.71-0.80$

$0.81-0.90$

$0.91-0.94$

$0.95-0.98$

0.99

0.25

0.35

0.45

0.55

0.65

0.75

0.85

0.92

0.96

0.99

2
2
2

2

0

0
1

1
0
0

0

0

0
0

0

Total Default

Total Non-Default

7

67507

67514

34525

34572

11
15
18
8
8
3
1
0
0
0
0
0
0

487
43

43
18

18
36
24

24

18

6

6$$
\begin{aligned}
& 1 \\
& 0 \\
& 3
\end{aligned}
$$

199

487

686

22843

$\begin{array}{rr}6437 & 375 \\ 12137 & 8187\end{array}$

8562

123535

Mean
Median
St.Dev
3.43192sigma-E(L)
2.32634sigma-E(L)
1.64485sigma-E(L)
$\quad 99.97 \%$
$\quad 99.00 \%$
$\quad 95.00 \%$

$\begin{array}{cccc}\mathbf{0 . 0 0 2 \%} & & \mathbf{0 . 0 1 5 \%} & \\ \mathbf{0 . 0 0 0 \%} & & \mathbf{0 . 0 0 0 \%} & \\ \mathbf{0 . 2 6 1 \%} & & \mathbf{0 . 2 8 6 \%} & \\ \mathbf{0 . 8 9 2 \%} & & \mathbf{0 . 9 6 7 \%} & \\ \mathbf{0 . 6 0 4 \%} & & \mathbf{0 . 6 5 1 \%} & \\ \mathbf{0 . 4 2 7 \%} & & \mathbf{0 . 4 5 6 \%} & \\ \mathbf{0 . 0 0 0 \%} & \mathbf{2 0 . 3} & \mathbf{1 4 . 9 8 5 \%} & \mathbf{1 0 . 4} \\ \mathbf{0 . 0 0 0 \%} & \mathbf{6 7 5 . 1} & \mathbf{0 . 0 0 0 \%} & \mathbf{3 4 5 . 7} \\ \mathbf{0 . 0 0 0 \%} & \mathbf{3 3 7 5 . 7} & \mathbf{0 . 0 0 0 \%} & \mathbf{1 7 2 8 . 6}\end{array}$

$\mathbf{0 . 1 3 1 \%}$

$\mathbf{0 . 0 0 0 \%}$

$1.421 \%$

4.747\%

$3.176 \%$

$2.207 \%$

$\mathbf{5 4 . 8 6 9 \%}$

$\mathbf{0 . 0 0 0 \%}$

$\mathbf{0 . 0 0 0 \%}$

$1.088 \%$

$\mathbf{0 . 0 0 0 \%}$

$\mathbf{4 . 5 7 3 \%}$

$14.605 \%$

$9.550 \%$

$6.434 \%$

$3.7 \quad 83.912 \%$

$122.0 \quad 33.912 \%$

$610.10 .000 \%$ 
Table 8

FREQUENCY DISTRIBUTION OF LOSSES

(PRINCIPAL AND COUPON), (1981 - 9/1999)

BY RATING ONE YEAR BEFORE DEFAULT

(NORMAL AND ACTUAL LOSS DISTRIBUTIONS)

(Based on Number of issues) - Poisson Process for Default

$\begin{array}{ccc}\begin{array}{c}\text { Range of } \\ \text { Default Losses }\end{array} & \text { Midpoint } & \text { A } \\ 0 & 0 & 67507 \\ 0.01-0.10 & 0.05 & 2 \\ 0.11-0.20 & 0.15 & 2 \\ 0.21-0.30 & 0.25 & 2 \\ 0.31-0.40 & 0.35 & 0 \\ 0.41-0.50 & 0.45 & 0 \\ 0.51-0.60 & 0.55 & 1 \\ 0.61-0.70 & 0.65 & 0 \\ 0.71-0.80 & 0.75 & 0 \\ 0.81-0.90 & 0.85 & 0 \\ 0.91-0.94 & 0.92 & 0 \\ 0.95-0.98 & 0.96 & 0 \\ 0.99 & 0.99 & 0 \\ 1 & 1 & 0\end{array}$

BBB
34525
26
16
4
1
0
0
0
0
0
0
0
0
0

Total

Total Non-Default

$$
7
$$

67507

47

Total
Mean
Median
St.Dev
3.43192sigma-E(L)
2.32634sigma-E(L)
1.64485sigma-E(L)
$\quad$ 99.97\%
$\quad 99.00 \%$
$\quad 95.00 \%$

67514

34525

34572

$0.002 \%$

$\mathbf{0 . 0 0 0 \%}$

$\mathbf{0 . 2 6 1 \%}$

$0.892 \%$

$\mathbf{0 . 6 0 4 \%}$

$0.427 \%$

$\mathbf{0 . 0 0 0 \%}$

$\mathbf{0 . 0 0 0 \%}$

$\mathbf{0 . 0 0 0 \%}$

$0.015 \%$

$\mathbf{0 . 0 0 0 \%}$

$\mathbf{0 . 2 8 6 \%}$

$\mathbf{0 . 9 6 7 \%}$

$\mathbf{0 . 6 5 1 \%}$

$\mathbf{0 . 4 5 6 \%}$

$\mathbf{0 . 0 1 5 \%}$

$\mathbf{0 . 0 0 0 \%}$

$\mathbf{0 . 0 0 0 \%}$

BB

B

CCC \&

Total

default rate $m$ per 100

loans in the portfolio

0.010

0.136

$\mathbf{9 9 . 9 7 1 \%}$
$\mathbf{9 9 . 2 8 8 \%}$
$\mathbf{8 8 . 3 0 3 \%}$

12137
11
15
18
8
8
3
1
0
0
0
0
0
0

8187

81

89

81

62

29

17

10

4

0

0

0

64

12137

375

8187

12201

8562

$\mathbf{0 . 1 3 1 \%}$

$\mathbf{0 . 0 0 0 \%}$

$1.421 \%$

$4.747 \%$

$3.176 \%$

$\mathbf{2 . 2 0 7 \%}$

$\mathbf{0 . 3 9 3 \%}$

$0.262 \%$

$\mathbf{0 . 1 3 1 \%}$

0.525

Sources: Standard \& Poor's, NYU Salomon Center Default Data Base

$99.979 \%$
$99.792 \%$
$98.368 \%$

\begin{tabular}{|c|c|}
\hline $1.088 \%$ & \\
\hline $0.000 \%$ & \\
\hline $4.573 \%$ & \\
\hline $14.605 \%$ & \\
\hline $9.550 \%$ & \\
\hline $6.434 \%$ & \\
\hline $13.055 \%$ & 13 \\
\hline $8.704 \%$ & 9 \\
\hline $7.616 \%$ & 8 \\
\hline 4.380 & \\
\hline & $99.967 \%$ \\
\hline & $99.629 \%$ \\
\hline & $97.098 \%$ \\
\hline
\end{tabular}

487
43
18
36
24
24
18
21
5
6
0
1
0
3

122843

163

140

141

95

61

39

32

10

0

1

0

692

122843

123535

$118 \%$

$\mathbf{0 . 1 5 0 \%}$

$\mathbf{0 . 0 0 0 \%}$

$0.000 \%$

$\mathbf{2 0 . 5 4 9 \%} \quad \mathbf{2 . 4 8 8 \%}$

$60.406 \%$

$\mathbf{3 7 . 6 8 7 \%} \quad \mathbf{5 . 6 3 9 \%}$

$\mathbf{2 3 . 6 8 3 \%} \quad \mathbf{3 . 9 4 3 \%}$

485.668\% $\quad 49 \quad 0.449 \%$

$\begin{array}{lll}414.841 \% & 42 & 0.300 \%\end{array}$

374.369\% $38 \quad 0.150 \%$

29.009

0.560 
Table 9

MONTE-CARLO SIMULATION OF LOSS RATES USING DATA 1981 - 6/1999

Simulated loss rates $(\%)$

Confidence Level

\begin{tabular}{|c|c|c|c|c|c|c|c|c|}
\hline Portfolio & Portfolio size (\$b) & mean & $95 \%$ & $97.5 \%$ & $99 \%$ & $99.5 \%$ & $99.9 \%$ & $99.95 \%$ \\
\hline 1. 13\% < BBB (P.P.) & 1.00 & 0.109 & 0.468 & 0.55 & 0.673 & 0.767 & 1.007 & 1.112 \\
\hline 2. $50 \%<$ BBB (Loans) & 1.00 & 0.409 & 1.106 & 1.28 & 1.486 & 1.657 & 2 & 2.18 \\
\hline 3. $A A A, A A, A$ & 1.00 & 0.003 & 0 & 0 & 0.05 & 0.25 & 0.55 & 0.55 \\
\hline 4. BBB & 1.00 & 0.015 & 0.15 & 0.15 & 0.25 & 0.3 & 0.4 & 0.4 \\
\hline 5. BB & 1.00 & 0.131 & 0.55 & 0.7 & 0.9 & 1 & 1.25 & 1.35 \\
\hline 6. B & 1.00 & 1.085 & 2.2 & 2.5 & 2.85 & 3.05 & 3.6 & 3.8 \\
\hline 7. CCC \& lower & 1.00 & 10.119 & 13.6 & 14.35 & 15.2 & 15.95 & 17.1 & 17.56 \\
\hline
\end{tabular}


Table 10

FREQUENCY DISTRIBUTION OF LOSSES

(PRINCIPAL AND COUPON), (1981 - 9/1999)

BY RATING ONE YEAR BEFORE DEFAULT

(NORMAL AND ACTUAL LOSS DISTRIBUTIONS

(Based on Number of Issuers)

$\begin{array}{cc}\begin{array}{c}\text { Range of } \\ \text { Default Losses }\end{array} & \text { Midpoint } \\ 0 & 0 \\ 0.01-0.10 & 0.05 \\ 0.11-0.20 & 0.15 \\ 0.21-0.30 & 0.25 \\ 0.31-0.40 & 0.35 \\ 0.41-0.50 & 0.45 \\ 0.51-0.60 & 0.55 \\ 0.61-0.70 & 0.65 \\ 0.71-0.80 & 0.75 \\ 0.81-0.90 & 0.85 \\ 0.91-0.94 & 0.92 \\ 0.95-0.98 & 0.96 \\ 0.99 & 0.99 \\ 1 & 1\end{array}$

BB\&B CCC\& Lower

Total

10308

$\begin{array}{cc}294 & 30246 \\ 4 & 18 \\ 8 & 22 \\ 11 & 31 \\ 11 & 36 \\ 11 & 36 \\ 9 & 47 \\ 17 & 53 \\ 12 & 45 \\ 7 & 27 \\ 1 & 14 \\ 2 & 4 \\ 0 & 1 \\ 0 & 0\end{array}$

Total Default

14

19644

227

93

334

10308

294

30246

Total

19658

10535

387

30580

Mean
Median
St.Dev
3.43192sigma-E(L)
2.32634sigma-E(L)
1.64485sigma-E(L)
99.97\%
99.00\%
95.00\%

$\mathbf{0 . 0 3 6 \%}$

$0.000 \%$

$1.154 \%$

$0.000 \%$

$12.078 \%$

$\mathbf{0 . 0 0 0 \%}$

$\mathbf{8 . 5 6 5 \%}$

$\mathbf{2 4 . 5 2 1 \%}$

$\mathbf{5 . 2 0 8 \%}$

$28.240 \%$

72.077\%

$18.771 \%$

$44.967 \%$

$12.934 \%$

$2.477 \%$

$\mathbf{5 4 . 9 6 4 \%}$

$0.000 \%$

5.9
196.6

$\mathbf{9 0 . 8 4 6 \%}$

$0.000 \%$

982.9

$0.000 \%$

3.2

$\mathbf{8 3 . 9 2 2 \%}$

$72.922 \%$

$62.922 \%$

$\begin{array}{cc}3.9 & 14.426 \% \\ 19.4 & 0.000 \%\end{array}$

Sources: Standard \& Poor's, NYU Salomon Center Default Data Base 


\section{TABLE 11}

An Alternative Risk Weighting Proposal for Bank Corporate Loans

\begin{tabular}{|l|c|c|c|c|}
\hline \multirow{3}{*}{ Corporates } & AAA to AA- & A+ to BBB- & BB+ to B- & Below \\
\cline { 2 - 5 } & $10 \%$ & $30 \%$ & $100 \%$ & $150 \%$ \\
\hline
\end{tabular}


FIGURE 1

Proportion of Bonds in Different BIS Proposed Buckets

(1989-1998)

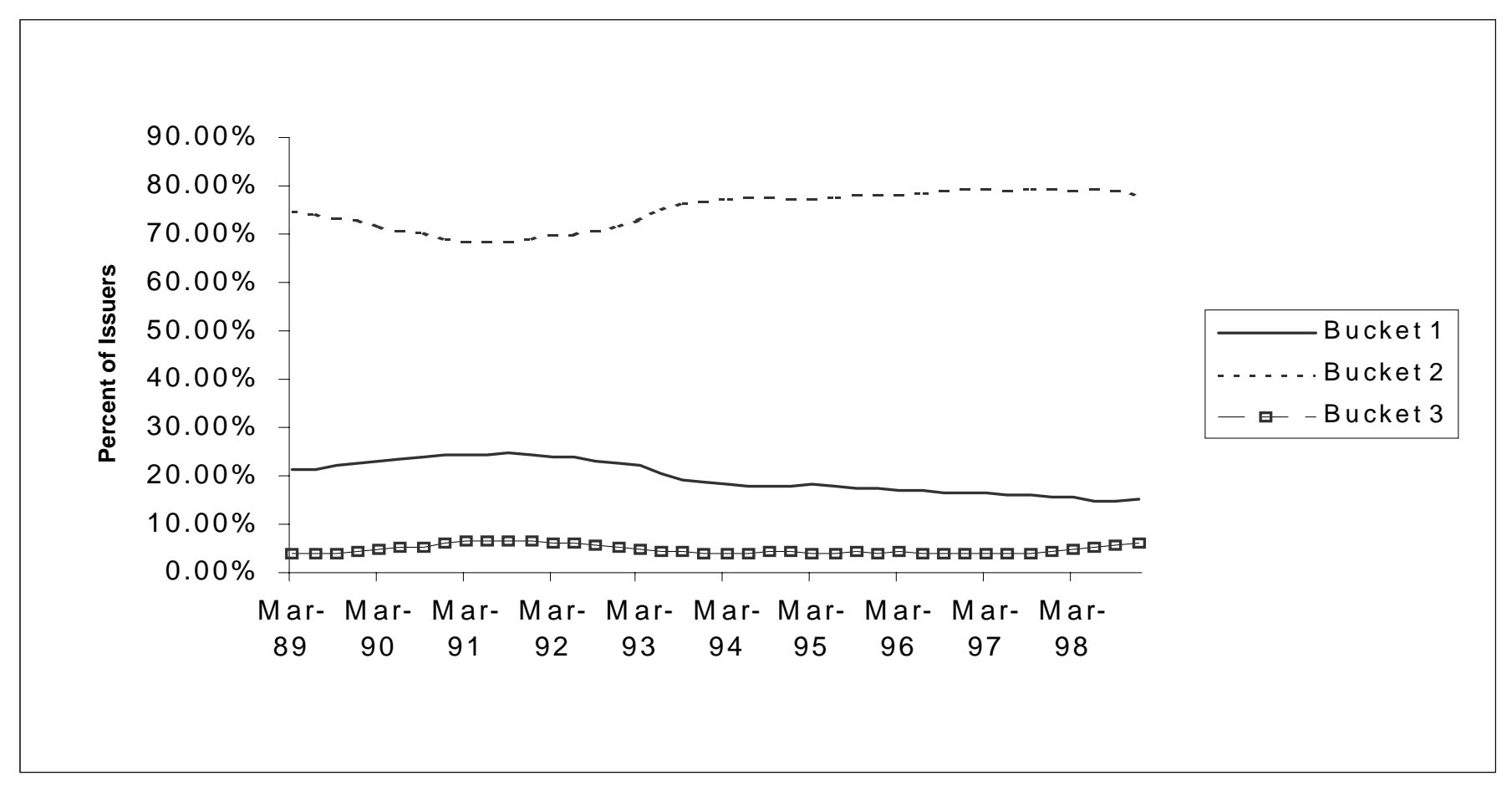

Source: Moody’s Investor Services, New York 
FIGURE 2

Proportion of Bonds in Different BIS Proposed Buckets

(1989-1998)

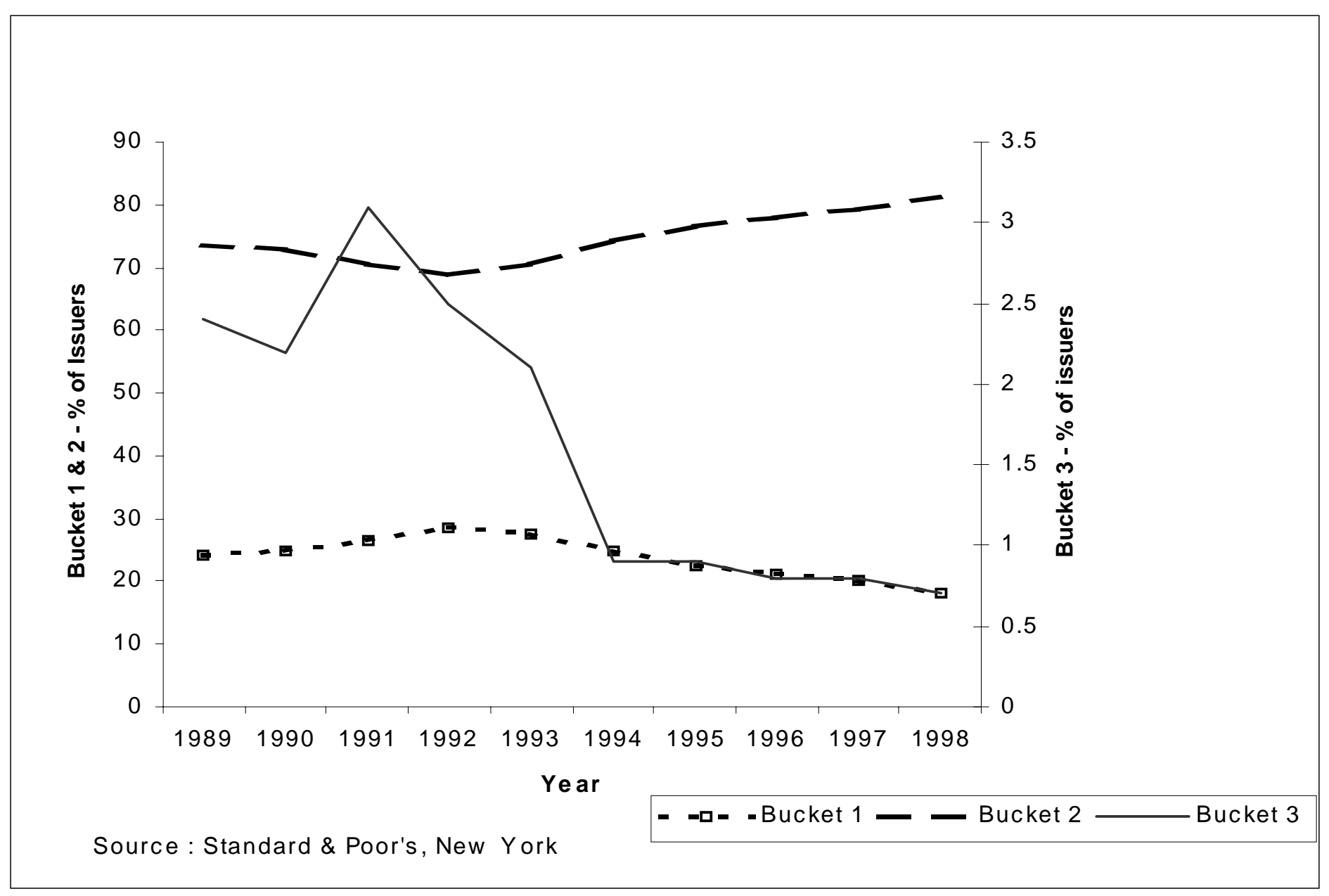

